\title{
The Fabric of Polycrystalline Ice Deformed in Simple Shear: Experiments in Torsion, Natural Deformation and Geometrical Interpretation
}

\author{
J. L. BOUCHEZT and P. DUVALt \\ †Laboratoire de Tectonophysique, Université de Nantes, 2 Chemin de la \\ Houssinière, 44072 Nantes-Cedex \\ $\ddagger$ Laboratoire de Glaciologie, C.N.R.S., Domaine Universitaire, BP 53, 38041 \\ Grenoble-Cedex
}

(Received November 2, 1981; in final form April 27, 1982)

Three cylinders of artificial ice have been deformed in torsion at about $-10^{\circ} \mathrm{C}$ up to finite shear strains $\gamma$ of $0.6,0.95$ and 2. The initial random lattice orientation rapidly evolves into a bimodal distribution of the basal slip planes as already observed by Kamb (1972) and Duval (1981) for low-strains experiments near the melting point. For the $\gamma=0.6$ and 0.95 experiments, one family of grains $(>50 \%)$ corresponds to basal planes tending to parallel the imposed shear plane; the basal planes of the other family make a broader maximum at about $60^{\circ}$ from the shear plane. The direction of minimum concentration between the two populations approximately corresponds to the flattening plane or to the elongation direction of the strain ellipsoid. With increasing strain $(\gamma=2)$ the second submaximum vanishes and only the principal maximum parallel to the shear plane remains. This evolution is conformable with the data of Hudleston (1977) in a natural shear zone in glacial ice; it also compares remarkably well with Etchecopar's (1977) geometrical computer model of simple shear in the same range of $\gamma$ values. Single slip on the basal plane with no preferential slip direction in that plane can explain the analogy between fabrics in ice deformed in plane strain and fabrics obtained from the two-dimensional computer model.

The bimodal distribution reflects predominant slip on the basal plane; the progressively increasing heterogeneous strain enhances internal distorsion, rigid body rotation and recrystallization of grains unfavorably oriented for further slip, leading to the unimodal distribution. The adequacy of fabric analyses to infer the strain regime and the sense of shear in plastically deformed rocks is strengthened. 


\section{INTRODUCTION}

Anisotropy of the lattice orientations in polycrystalline materials, called "textures" by metallurgists and crystalline "fabrics" or "lattice preferred orientations" = L.P.O. by geologists is now a matter of numerous studies in the earth sciences due both to potential applications to the kinematic analyses of geological bodies and to the important role of the anisotropic properties of rocks in geology such as for flow laws. Since the beginning of the seventies, in conjunction with a better understanding of the deformation mechanisms in crystals, L.P.O. studies became increasingly frequent and the kinematic interpretations of rock tectonic histories became more firmly established (Nicolas and Poirier, 1976). An important part of recent L.P.O. studies in rocks is devoted to peridotites and quartzites. In such rocks homogeneously deformed by predominantly intracrystalline slip, it appears that solid state flow on the scale of the aggregate is mainly achieved by the activity of a dominant single slip system, or a single slip direction (Nicolas et Vialon, 1980). Under these conditions and as soon as strain is sufficiently large for a given shear regime, the slip planes parallel the shear plane and the slip directions parallel the shear direction. This is particularly clear for peridotites in which three behavioural domains of olivine can be distinguished with increasing temperature (Nicolas et Vialon, 1980). The behaviour of quartz is more complex and the experimental controls are less complete than for olivine, but it is believed that the $\langle 11 \overline{2} 0\rangle$ slip direction prevails in natural quartz-tectonites (Christie et al., 1964; Bouchez et al., 1979), along with the (0001) basal plane at low-temperature (greenschists facies) and other planes in a zone around the $\langle 11 \overline{2} 0\rangle$ direction for higher temperatures (Bouchez and Pêcher, 1981).

The dominant "single slip behaviour" is here illustrated using polycrystalline ice as an analogue of usual rocks (see also Wilson, 1982), easy to deform under geometrically controlled conditions. Comparing the resulting L.P.O. with that of ice naturally deformed under similar conditions and with that of the geometrical model of Etchecopar (1977) enables a better understanding of the mechanism of L.P.O. formation.

Ice formed at $0^{\circ} \mathrm{C}$ by freezing water at room pressure has an hexagonal structure ( $I h$ ice of Hobbs, 1974). Its intracrystalline plastic deformation is achieved by slip on the basal (0001) plane (MacCornell, 1891; Steinemann, 1958 ) and along the $\langle 11 \overline{2} 0\rangle$ direction (Glen and Jones, 1967). Non-basal slip bands have been recorded (see Muguruma and Higashi, 1963) but in fact most of the observed dislocations in ice have a Burgers' vector of $\frac{1}{3}\langle 11 \overline{2} 0\rangle$. In addition Glen (1975) and Higashi (1967) showed that the stress which is 

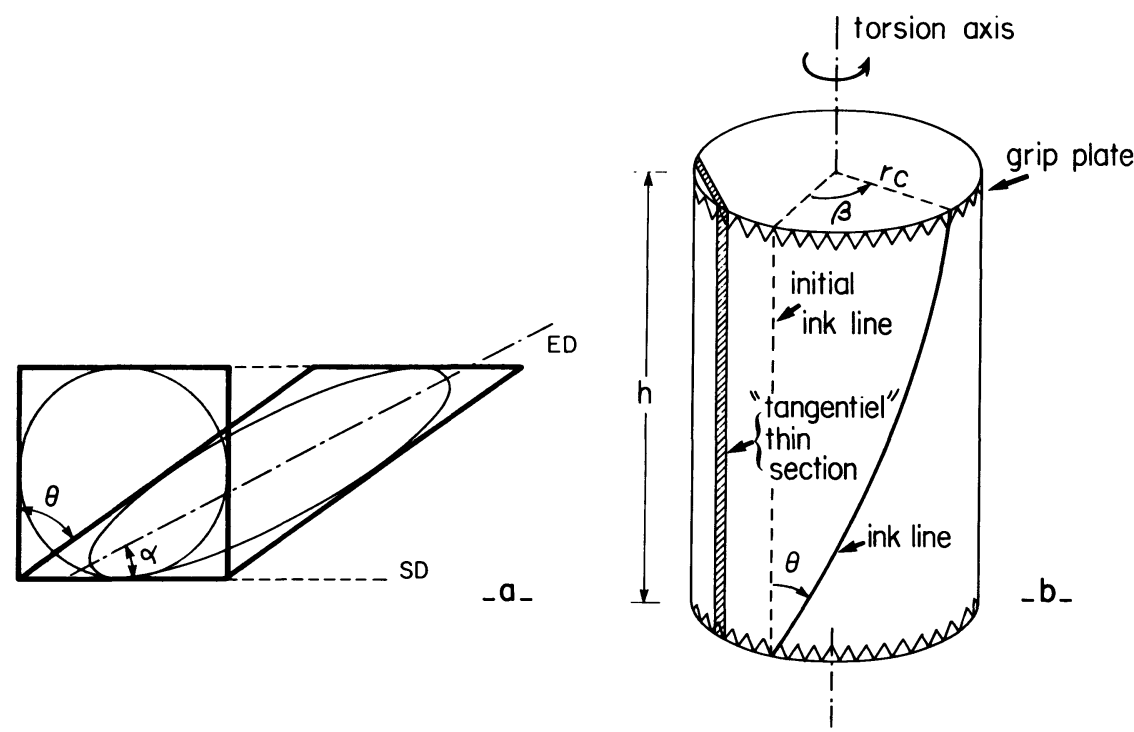

FIGURE 1 Simple shear (a) and torsion (b) geometry.

a) The plane of deformation is parallel to paper; ED, extension direction or long axis of the strain ellipse; SD, shear direction.

b) The sample is gripped at its ends $\left(r_{c} \sim 40 \mathrm{~mm}: h \sim 120 \mathrm{~mm}\right)$. The ink line outlines the strain variations along the cylinder (see Figure 2). The thin sections for c-axis orientation data are near-peripheral tangential sections $(\sim 1 \mathrm{~mm}$ in thickness and $\sim 2 \mathrm{~cm}$ in width).

necessary to deform a single crystal of ice in a non-basal plane is more than one order of magnitude higher than for basal plane activation which needs less than one bar at $-20^{\circ} \mathrm{C}$.

The simple shear geometry used is sketched in Figure 1a; $\theta$ is the angle of shear; the shear strain is more often referred by its $\gamma=\tan (\theta)$ value. Note that the deformation due to simple shear is in the plane perpendicular to the shear plane and parallel to the shear direction. In that plane, the direction of finite extension (ED) or long axis of the strain-ellipse makes an angle $\alpha$ with the shear direction, with $\alpha=0.5 \tan ^{-1}(2 / \tan \theta)$. In the following, the sense of shear will always be dextral as in Figure 1a.

\section{TORSION EXPERIMENTS}

\section{Experimental procedure}

Simple shear in the laboratory is achieved by constant-stress torsion experiments of cylindrical samples (Figure 1b). That procedure is simpler to conduct than using directly a "shear-box," especially if high shear strains are desired. 


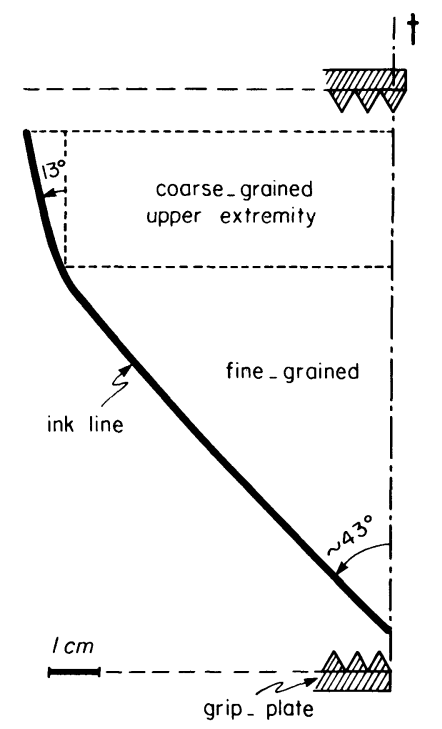

FIGURE 2 Heterogeneous strain in experiment E2. After development of the cylinder surface on a plane $(t=$ trace of the torsion axis), the ink line shows two roughly linear domains corresponding to two homogeneously deformed parts of the cylinder. Due to an excess of water relative to snow during the sample preparation on the upper part of the cylinder, a coarse-grained aggregate developed and deformed at a constant but lower average strain-rate than the bottom part. The microstructure of this sample is shown in Figure $3 \mathrm{~b}$.

In ice, torsion experiments have been realized by Steinmann (1958), Kamb (1972) and Duval (1981). The apparatus used here has already been described (Duval, 1976b).

As seen in Figure 1, the imposed shear plane is normal to the axis of torsion; the shear direction in each point of the sample is normal to that axis, within the local shear plane. For a homogeneous torsion with an angle $\beta$ (radians) the shear strain $\gamma$ for a point located at a distance $r$ from the axis is: $\gamma \approx \beta r / h$, where $h$ is the height of the sample (here $h \sim 120 \mathrm{~mm}$ ). We see that the shear strain for a given $\beta$ is constant at a constant distance from the axis, and that the axis itself is a singular line where $\gamma=0$, whatever $\beta$. That singularity may be avoided using hollowed cylinders (Kamb, 1972); they have not been used here as the L.P.O. measurements have been conducted far from the axis, near the periphery of the samples $(r \sim 40 \mathrm{~mm})$.

\section{E1, E2 and E3 experiments}

The polycrystalline samples were obtained by filling a cylindrical container with snow, saturating the snow with previously boiled water, and allowing the water to freeze in an air-depleted condition. This technique is that modified 

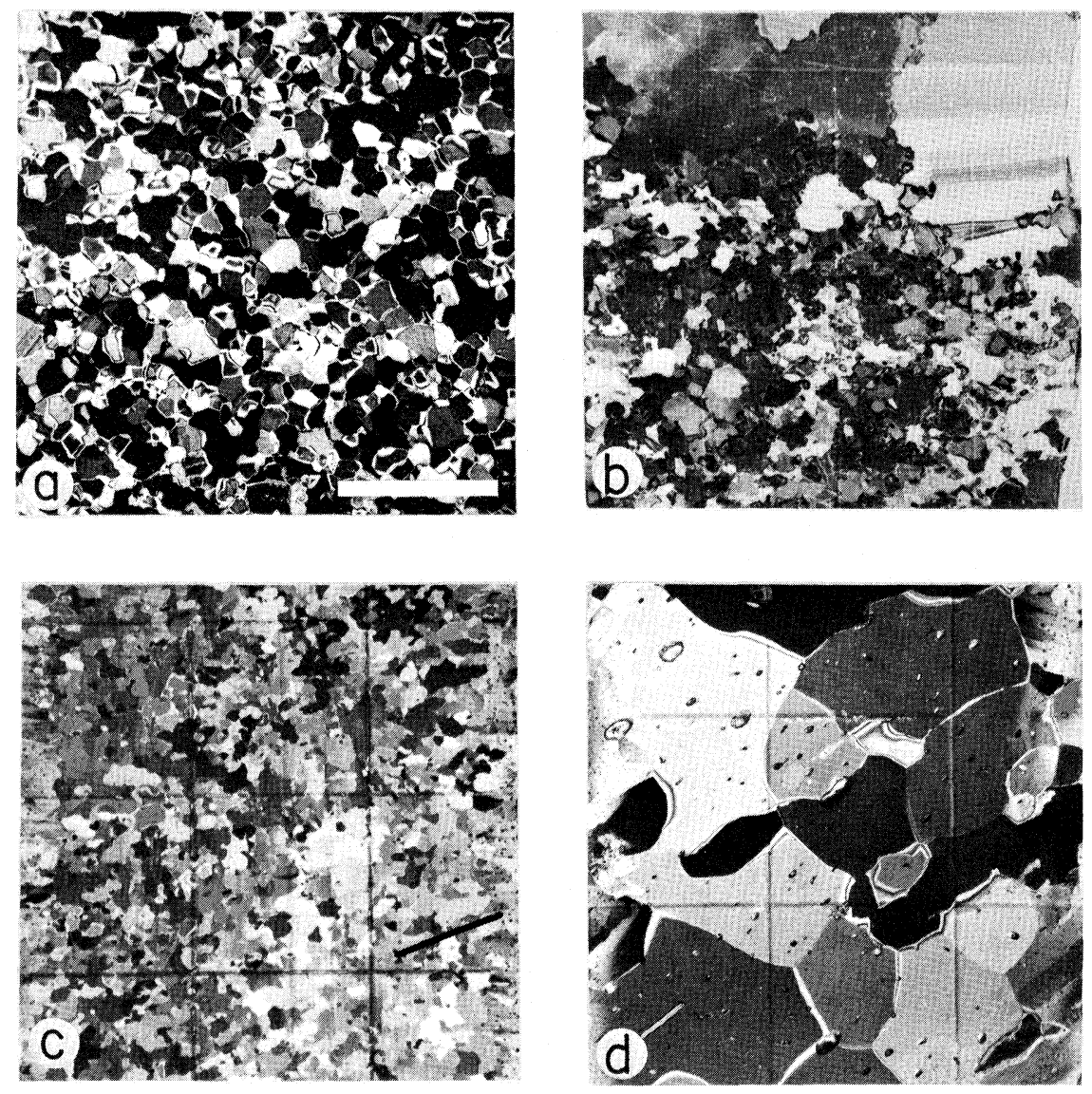

FIGURE 3 Microstructures of the experimentally deformed ice (crossed polars).

a) The undeformed artificial aggregate; section normal to the axis of the cylinder. Polygonal equant mosaic. Scale bar is $10 \mathrm{~mm}$.

b) Experiment E2. Radial section (containing the axis of the deformed cylinder) showing the coarse-grained (upper) to fine-grained (lower) transition responsible for the strain-rate inhomogeneity (see Figure 2). Notice the kink-bands, with boundaries parallel to [0001] in the upper-right corner. Square grid is $10 \mathrm{~mm}$.

c) Experiment E3. Tangential section. Fine-grained aggregate. The strong lattice fabric is reflected by the rather smooth contrasts. The black bar underlining a local elongated grain foliation is parallel to $\operatorname{ED}\left(\alpha \sim 22^{\circ}\right)$. Square grid is $10 \mathrm{~mm}$.

d) Experiment E1. Tangential section. After a static recrystallization of $24 \mathrm{~h}$ duration at $-1^{\circ} \mathrm{C}$. The grain-size increased from 35 grains $/ \mathrm{cm}^{2}$ (initial) to 3.2 grains $/ \mathrm{cm}^{2}$. Elongated bubbles $(\alpha$ : $45^{\circ}$ to $30^{\circ}$ ) have their mean elongation subparallel to ED (white bar; $\alpha \sim 37^{\circ}$ ). With the exception of the triple-junction site (low centre), the bubbles did not greatly affect the grain-boundary migration. Square grid is $10 \mathrm{~mm}$. 
from Kamb (1972) by Le Gac (1980) in order to minimize the density of air-bubbles. The ice crystals within the aggregate (Figure 3a) are subequant in shape, 2.-3. $\mathrm{mm}$ in diameter and have c-axis orientations close to random (Le Gac, 1980).

Three torsion experiments have been performed for different $\gamma$ values (calculated for the peripheral thin sections which were used here for a cylinder radius varying from $2-3 \mathrm{~mm}) \gamma_{1}=0.6, \gamma_{2}=0.95$ and $\gamma_{3}=2$., shear stresses were about 4 bars. Temperatures were respectively, $T_{1}=-7^{\circ} \mathrm{C}, T_{2}=-12^{\circ} \mathrm{C}$ and $T_{3}=-10^{\circ} \mathrm{C}$. The duration of the experiments was, $t_{1}=25$ days, $t_{2}=35$ days and $t_{3}=62$ days. Average strain rates were $\bar{\gamma}=10^{-7} \mathrm{sec}^{-1}$ for E1 and E2. In E3 $\dot{\gamma}$ increased from $10^{-7}$ to $10^{-6} \mathrm{sec}^{-1}$. The homogeneity of the strain along the cylinders was visualized by the distorsion of ink lines which were initially parallel to the torsion axis (vertical). Figure 2 shows an example of strain heterogeneity encountered in E2 due to an initial heterogeneity in the grain-size distribution along the cylinder (see Figure $3 \mathrm{~b}$ ). The preferred orientation data reported here for E2 are relative to the homogeneously strained bottom part of the sample $\left(\gamma_{2}=0.95\right)$. As soon as the samples were unloaded they were cold-stored, then thin sectioned and photographed. Storage at $-20^{\circ} \mathrm{C}$ prevented a microstructural readjustment of the deformed aggregate at least for a period of several months. The thin sections used are the "tangential" ones (Figure 1), they are parallel to the plane of deformation, i.e. perpendicular to the shear plane and parallel to the shear direction, and provide near constant $\gamma$ values $(\Delta \gamma / \gamma \sim 5 \%)$.

\section{Microstructure}

With strain, the grain shapes evolve from subpolygonal (Figure 3a) to irregular and variously lobate (Figure $3 \mathrm{~b}$ and Figure 6). The grain-size distribution becomes more variable with large grains neighbouring smaller ones. The average grain-size keeps close to the initial one $\left(\sim 35\right.$ grains $\left./ \mathrm{cm}^{2}\right)$ for $\gamma=0.6$ (E1) but gets appreciably smaller for higher strains ( 50 grains $/ \mathrm{cm}^{2}$ for E2 and $>60$ grains $/ \mathrm{cm}^{2}$ for E3). The grains are frequently non-equidimensional (Figure 3c) but an average elongation direction is hard to recognize by eye, contrary to what is currently observed in foliated rocks or sometimes in naturally foliated ice (see Kamb, 1959). We found that a slight static recrystallization of the samples helps to better visualize a shape preferredorientation (Figure 4a). However, taking the unrecrystallized samples, the existence of a shape preferred-orientation can be shown by measuring the average spacing between successive grain-boundaries for the various directions in the thin section. This has been done for sample E1 (Figure 4b). Along the directions contained in the $\left(+50^{\circ}, 0^{\circ}\right)$ angular domain, the grain-boundary spacing is about $20 \%$ larger than the average spacing for the whole section. 

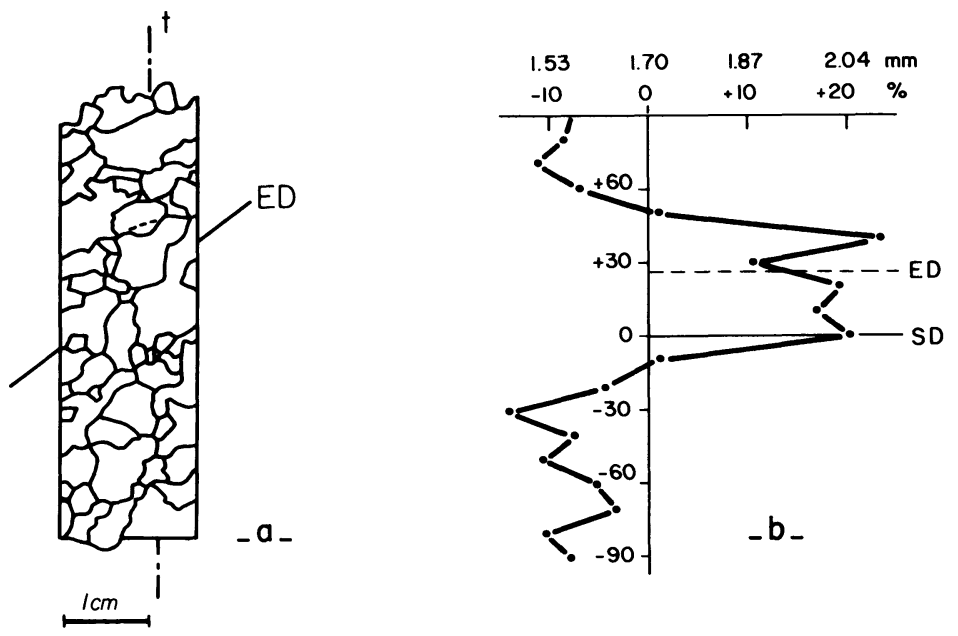

FIGURE 4 Shape preferred-orientation of the experimentally deformed aggregate, experiment E1.

a) Part of the deformed specimen was statically recrystallized during $6 \mathrm{~h}$ at $-1^{\circ} \mathrm{C}$. Tangential section; $t$, trace of the torsion axis. A weak foliation (average elongation direction of the grains), close to ED, is found to be easier to detect by eye than in the unrecrystallized sample (cf. Figure 6). Grain size: 11 grains $/ \mathrm{cm}^{2}$ against 35 in the unrecrystallized sample.

b) Unrecrystallized area (see Figure 6). The average spacing between successive grainboundaries is plotted as a function of the direction on the thin section. Orientation conventions same as for Figure $5 c$.

The ED direction, the theoretical elongation direction for simple shear, belongs to the wide angular domain which contains the preferred grainelongation. In fact the long axes of the deformed bubbles more closely parallel the ED direction than the grain elongation, as illustrated in the E1 sample (Figure 3d) which has bubbles particularly large in size.

\section{C-axis and basal plane orientations}

As for any uniaxial crystal, the optical determination of the L.P.O. in ice is reduced to that of the [0001] axis orientation. In cold rooms, the measurement is traditionally achieved using a universal stage under crossed-polars, without magnification nor hemispherical lenses (Rigsby, 1951; Schumsky, 1957); the inclination of the c-axis with respect to the optical axis is therefore corrected for the air-ice refraction. The use of a standard microscope with a U-stage is easier especially if the grain-size is small. Some orientation data have been collected in this manner, particularly those related to the orientation micromap (Figure 6). For sake of clarity the orientation data which 

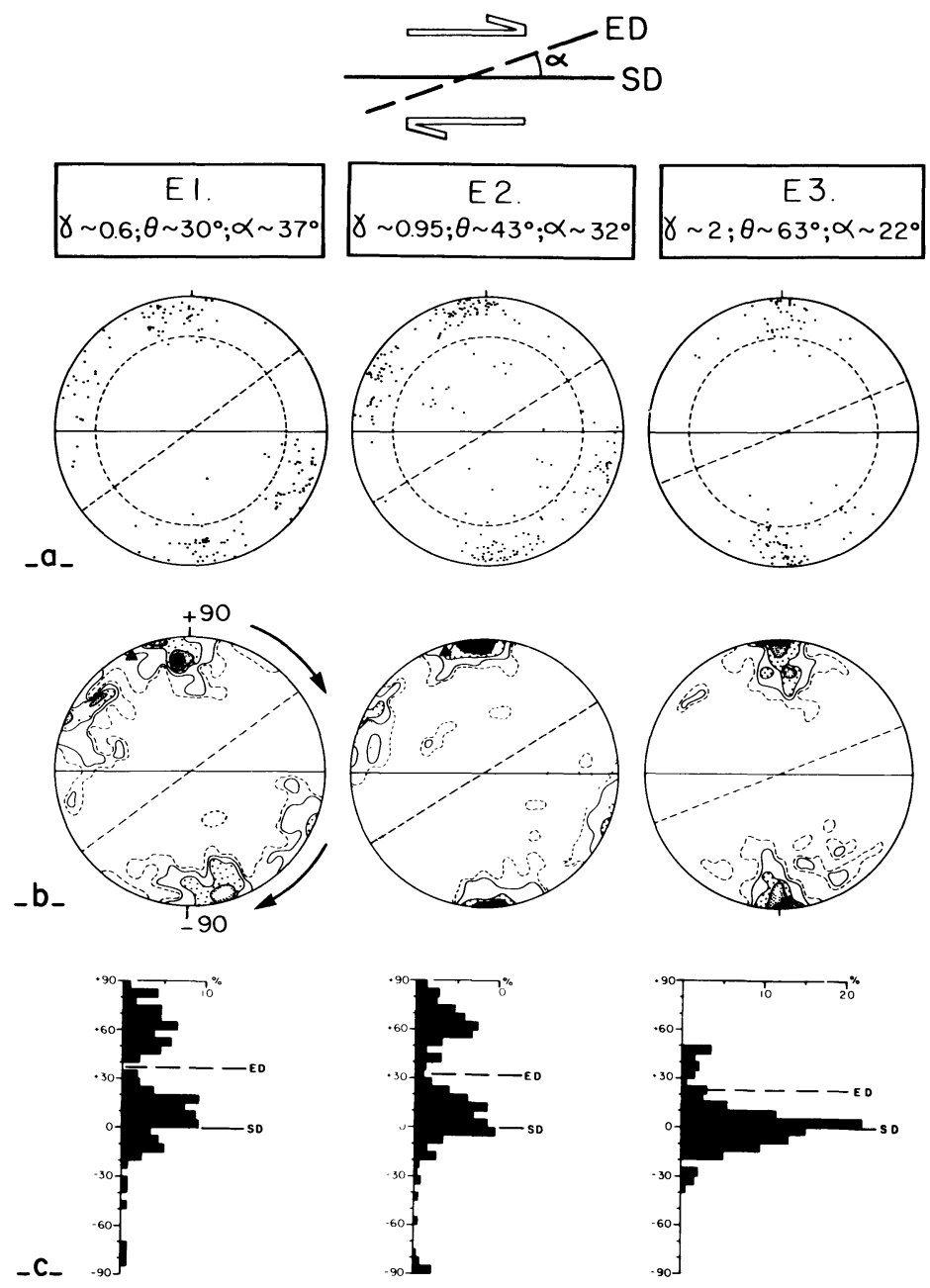

FIGURE $5 \mathrm{C}$-axis and basal plane orientations in ice for the torsion experiments E1, E2 and E3.

a) Orientation data for the c-axes, equal area diagrams. E1 147 points; E2 208 points; E3 100 points. The diagrams are parallel to the plane of the deformation. Solid $\mathrm{E}-\mathrm{W}$ line is the trace of the shear plane and the shear direction. Broken oblique line is the theoretical elongation direction for simple shear (compare with Figure $4 \mathrm{~b}$ ). The broken circular line has a radius of $70^{\circ}$.

b) Contoured c-axis diagrams. Orientations are the same as in a. Contours E1 0.7, 1.4, 2.8, 4.2, max. 5.6\%; E2 0.5, 1., 2., 4., 6., max. $7 \%$; E3 1., 2., 4., 6., max. $14 \%$. Counting area is $0.45 \%$ of the hemisphere area. Full triangle is the calculated best fitting axis of the distribution.

c) Histograms giving the angular distribution of the trace of the basal planes in the plane of the deformation. The angular convention $\left(+90^{\circ}\right.$ to $\left.-90^{\circ}\right)$ is given on the contoured diagram $\mathrm{E} 1 \mathrm{in} \mathrm{b}$. 
are given here are relative to a single section for each experiment:

1) for similar $\gamma$ values, the data obtained from other sections are not directly superposable but closely comparable;

2) the exploration of intermediate $\gamma$ values, using sections with smaller $r$ values, is consistent with the presented evolution of the orientations with strain.

The orientation data for the E1, E2 and E3 experiments are given in Figure 5. Figure 5a gives the point data for the c-axes. The diagrams are parallel to the plane of the deformation (i.e. parallel to the thin section planes). The trace of the imposed shear plane and shear direction (SD) are horizontal. The same data are contoured in Figure 5b. This representation better visualizes the orientation densities and the respective weights of the submaxima; these weights can also be compared using the position of the calculated best fitting axis (triangle). These diagrams contain the main features relative to the orientation of the ice crystals in a polycrystal deformed by simple shear. They are:

1) A strong preferred-orientation is rapidly attained with increasing strain. For the lowest $\gamma$ value ( 0.6 in E1), more than $90 \%$ of the c-axes are closer than $30^{\circ}$ to the plane of the deformation and $80 \%$ of them closer than $20^{\circ}$.

2) For low strains (E1, E2), the c-axes cluster into two submaxima. One of them (M1) is located about the pole of the shear plane; the other one (M2) is centred at about $60^{\circ}$ from M1 and "behind" it with respect to the sense of shear; M1 is heavier than M2. With increasing strain (E3) M1 grows at the expense of M2 which, at the same time, gets closer to M1.

Due to the measurement technique itself, the orientation data are relative to individual grains and are not weighted by the volume (or surface in section) they occupy. The micromap in Figure 6 (see caption) shows that the M1-M2 discrepancy is higher considering surfaces than number of grains.

Owing to the fact that most c-axes are located in a peripherical position on the diagrams, it is justified geometrically to study the orientation distribution of the trace of the basal planes (0001) using histograms in the plane of the deformation (Figure 5c). The histograms better emphasize the bimodal distribution of the basal planes and reveal:

1) Almost all the (0001) traces are gathered among the M1 and M2 clusters. Subdividing the half-plane between $+90^{\circ}$ and $-90^{\circ}$ as in Figure $5 \mathrm{c}$, we can see that less than $6 \%$ of the basal plane traces occupy the $-20^{\circ}$ to $-90^{\circ}$ angular domain for the three experiments.

2) The M1 (from ED to $-20^{\circ}$ ) and $M 2\left(+90^{\circ}\right.$ to ED) submaxima are clearly separated by a null-zone and are symmetrically disposed on each side of the 


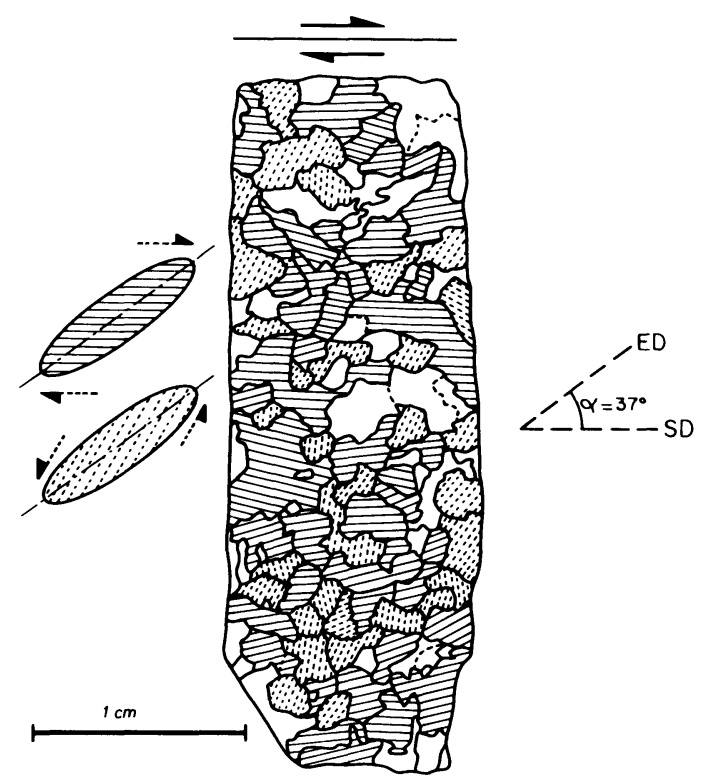

FIGURE 6 Micromap showing the bimodal distribution of the basal planes. Tangential section from experiment E1 $(\gamma=0.6)$. The blank areas correspond to zones where the grain-boundary distribution is confused. In the grains, the trace of the basal plane is marked by solid lines for orientations belonging to the M1 submaximum in the range $+35^{\circ}$ to $-20^{\circ}$ and by dashed-lines for the other orientations. For this figure, the M1 submaximum comprises $56 \%$ of the grains in number and which occupy nearly $65 \%$ of the whole surface. Of the sketched grains, the upper one is typical of the M1 submaximum and the lower one is typical of M2.

ED direction. The M1 and M2 populations can be more precisely quantified; M1 represents $58 \%$ of the whole in E1, $56 \%$ in E2 and $85 \%$ in E3; M2 represents $38 \%$ in E1 and E2 and less than $11 \%$ in E3. E1 and E2 appear to have similar preferred-orientations, in grain numbers, with a more regular bimodal distribution in $\mathrm{E} 2$.

The preliminary conclusion is that the basal slip plane within each ice crystal tends to parallel the imposed shear plane after a given total shear strain $(\sim \gamma=2)$ is attained. At lower $\gamma$ values the basal planes, which were initially randomly orientated, readily distribute into two distinct orientations. This conforms the data of Duval (1981) and Kamb (1972) for experiments conducted near the melting point. The latter author reports a readable bimodal distribution for a shear strain as low as $\gamma=0.29$. The micromap in Figure 6 gives an outline of these two families as they can be observed directly under crossed-polars by the light contrasts. The following example of a zone of shear in naturally deformed ice illustrates a similar evolution with increasing strain. 


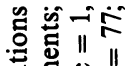

总实足

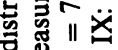

㲅

范䒹

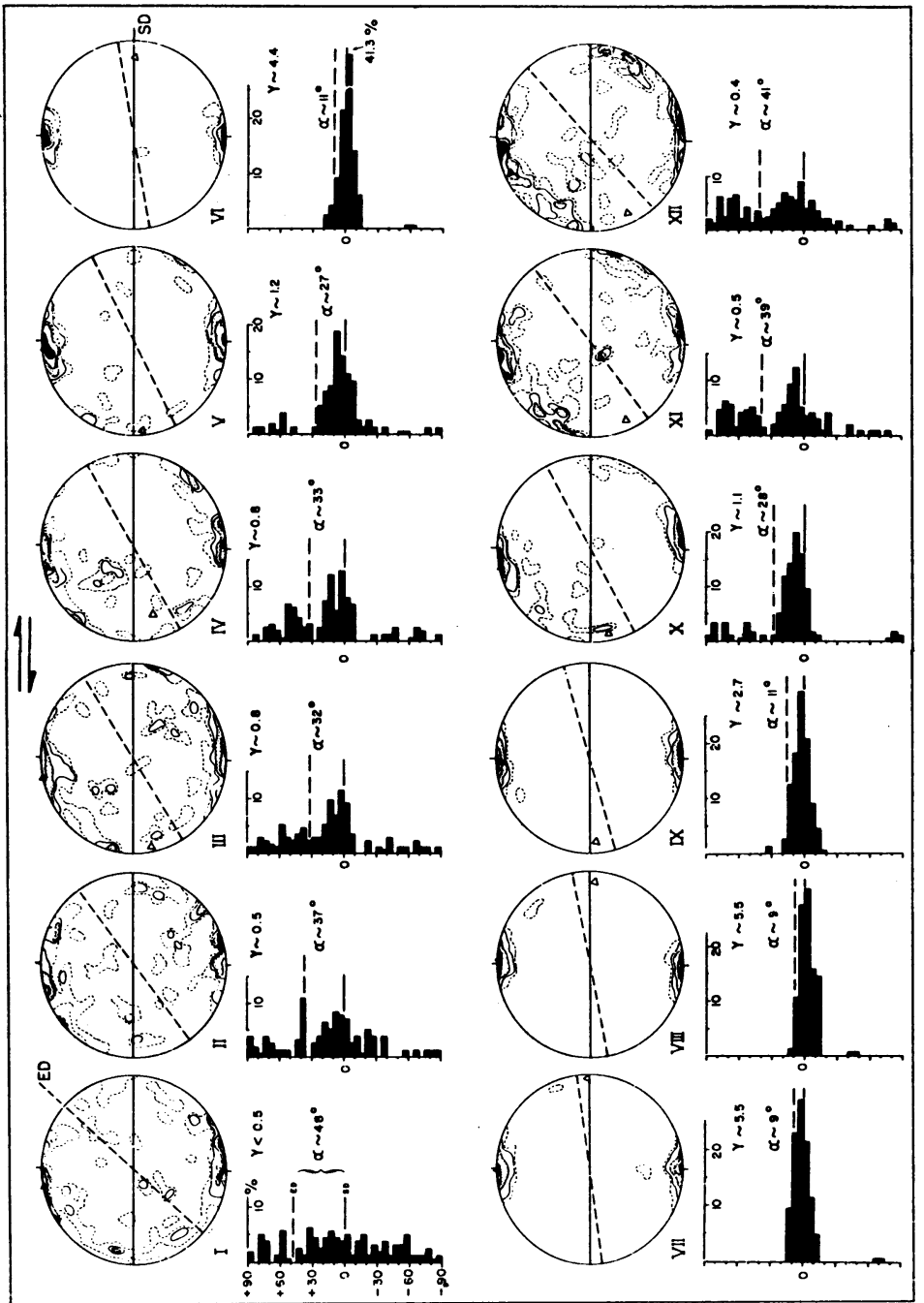

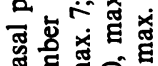
อี ํㅗㅁ D b ENin की - II II है 00 ôn क.

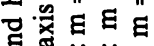

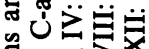

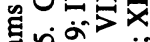

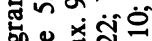
吾 . 证的 x m उँํำ उुํำ

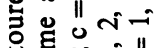

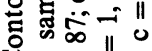

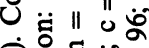
ㅎํㄹㅇㅛ

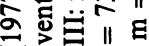
敋 1

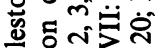

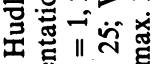

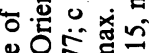
요 해

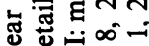

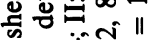

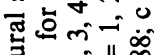
政 $\|_{\infty}^{\infty}$ ¿ ¿ E 0 Iㅣ 틴휴 ह 垔。

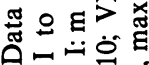
๘

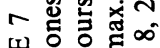

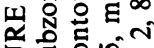

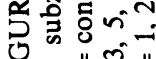
足㝴 


\section{COMPARISON WITH NATURALLY SHEARED ICE}

Despite the numerous studies dealing with the preferred-orientations of naturally deformed ice, few of them are available for a comparison with our simple shear experiments. The reasons are; the strain history in natural ice is complex, especially in glaciers, often with strong post-tectonic recrystallization and the in-situ geometrical conditions are generally unknown or, more simply, the structural framework is not reported in the published diagrams. In contrast, Hudleston (1977) presents a precise and welldocumented study of a narrow shear-zone in glacial ice and this is summarized in the following paragraph.

In Barnes Ice Cap (Canada), a shear zone pattern develops in an initially undeformed ice which is overriden by the advance of a glacier. The sampling was made in a shaft where the temperature was near constant at $-10^{\circ} \mathrm{C}$. One shear zone, twelve centimeters in thickness (distance between the shear zone boundaries within the plane of deformation) has been fully studied by Hudleston (1977) for its microstructures and c-axis orientations. The bubble elongation directions, drawing a typical sigmoidal pattern across the zone, helped to insure that simple shear was the main component of strain and allowed the calculation of $\gamma$ values. The shear zone was divided by Hudleston into twelve subzones (one centimeter each in thickness) each characterized by the same average $\gamma$ value (Figure 7), from I, the upper zone boundary, through VII and VIII (maximum $\gamma$ value of about 5.5), to XII, the lower zone boundary. The contoured c-axis diagrams and the corresponding histograms giving the distribution of the traces of the basal plane for subzones I to XII (Figure 7) have been reconstructed using Hudleston's raw orientation data; the conventions for the orientations are the same as for Figure 5; the $\alpha$ angle corresponds to the local bubble plunge, or angle between ED (extension direction given by the average bubble elongations) and SD (shear direction).

Hudleston's data can be summarized as follows:

1) For the lower strained subzone $I(\gamma<0.5)$, the histogram is rather "flat" but the c-axis diagram already shows a majority of points located close to the plane of the deformation (more than $70 \%$ of the points are closer than $30^{\circ}$ to it).

2) For the intermediate $\gamma$ values of subzones III-IV and XI-XII $(\gamma=0.4-0.8)$ the bimodal distribution on each side of ED is very well defined; the M2 submaximum tends to disappear with increasing strain $(\gamma=1.1-1.2)$ for subzones $\mathrm{V}$ to $\mathrm{X}$.

3) For the higher strained subzones VI to IX ( $\gamma=2.7-5.5)$, the basal plane 
distribution is unimodal and represented by the M1 maximum alone, centered about SD.

The above textural evolution, though more progressively illustrated, is comparable to that in E1-E3 (Figure 5). Histograms IV, XI and XII are similar to E1 and E2, and E3 $(\gamma=2.0)$ would be in intermediate position between subzones $\mathrm{V}(\gamma=1.2)$ and IX $(\gamma=2.7)$.

\section{ANALOGY WITH ETCHECOPAR'S MODEL}

This geometrical model (Etchecopar, 1974; 1977) describes the evolution of the shape and the lattice preferred orientations of an aggregate with an increasing planar pure and/or simple shear deformation. The crystalline aggregate is modelled in two-dimensions by a collection of jointed polygonal cells, each one having a unique slip system and with an initial random orientation (Figure 8a). A given final shape, imposed step by step to the aggregate by a boundary condition, is obtained (Figure $8 \mathrm{~b}$ ) by the deformation of each
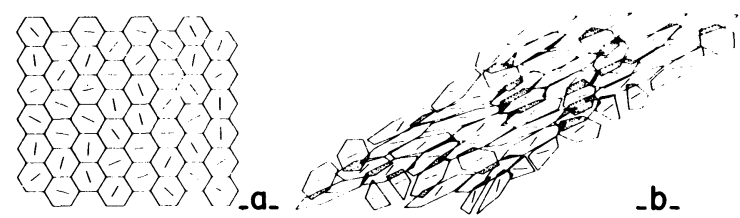

FIGURE 8 The geometrical model of Etchecopar (1977, p. 137).

a) Initial set of polygonal cells with randomly oriented slip directions.

b) After a dextral simple shear, of $\gamma=1.43\left(\theta=55^{\circ}\right)$; mark dots overlap areas.

constituent cell through the calculation of the transformation (internal homogeneous slip $\times$ rigid body rotation $\times$ translation) which minimizes the gaps and the overlaps with the neighbouring cells. Taking the case of a deformation by simple shear, this model defines an average extension direction (ED) for the aggregate close to the theoretical; the histograms of the orientation distribution of the slip directions (Figure 9) are comparable, in many respects, with that of ice.

For the lower $\gamma(0.7-1.43)$, the analogy is nearly one to one as noted below.

1) For $\gamma=0.7\left(\theta=36^{\circ}\right)$, the bimodal distribution is not yet well defined but almost $90 \%$ of the slip directions are distributed within the $+90^{\circ}+0-20^{\circ}$ angular domain (Figure 9a). 

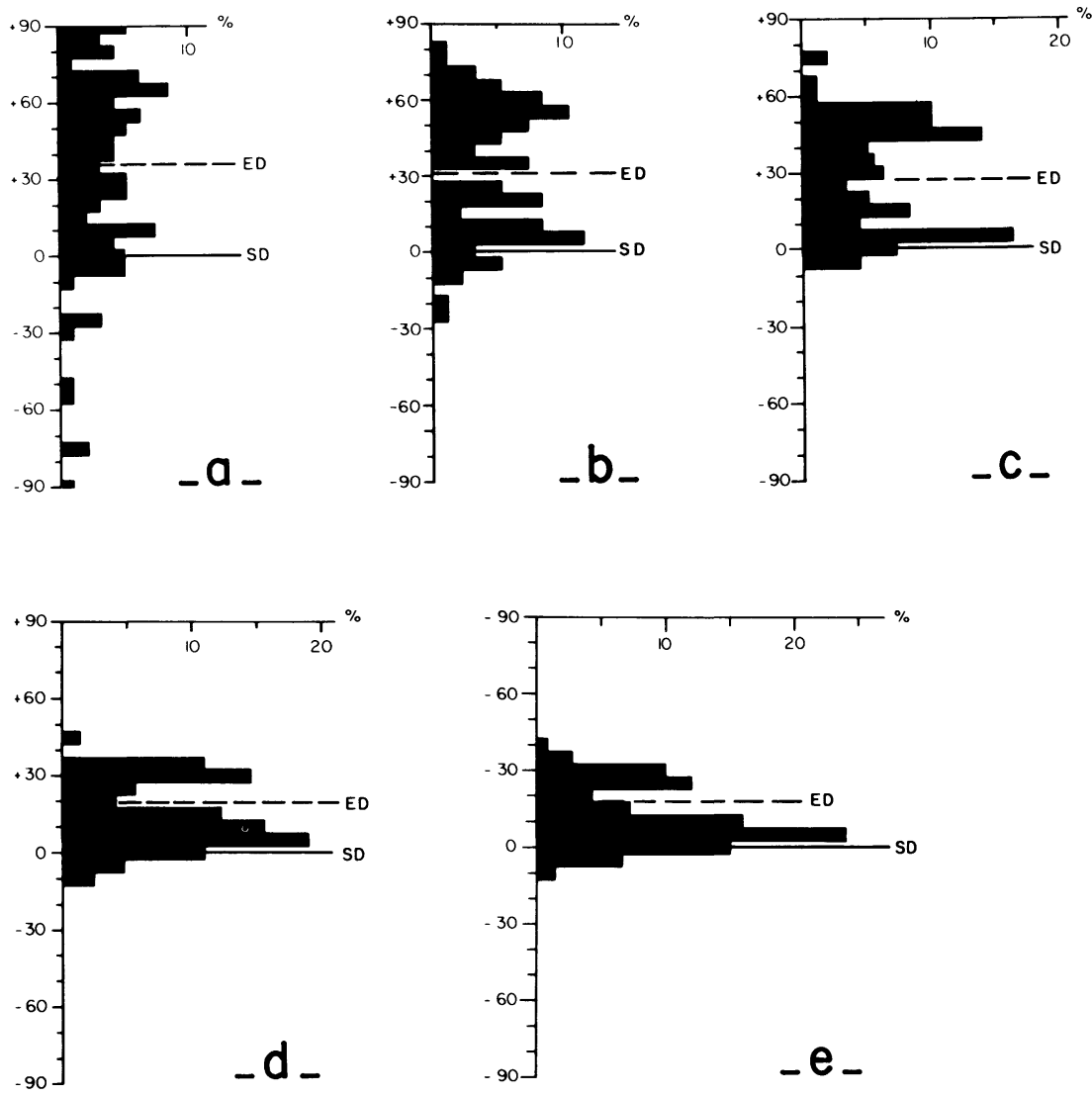

FIGURE 9 Distribution of the slip-lines predicted by Etchecopar's model for various $\gamma$ values in simple shear.

a $\gamma=0.7\left(\theta=36^{\circ}\right)$; b $\gamma=1.07\left(\theta=47^{\circ}\right)$; c $\gamma=1.43\left(\theta=55^{\circ}\right)$; d $\gamma=2.6\left(\theta=69^{\circ}\right)$; e $\gamma=2.9$ $\left(\theta=71^{\circ}\right)$. The frequencies are relative to the number of grains. In $\mathrm{a}, \mathrm{b}$ and $\mathrm{c}$, the cells are not subdivided whereas in $\mathrm{d}$ and e subdivision is allowed (locked grains, see text) giving a higher number of cells and promoting M1 at the expense of M2.

2) The bimodal distribution is clear for $\gamma=1.07\left(\theta=47^{\circ}\right)$ and gets stronger for $\gamma=1.43\left(\theta=55^{\circ}\right)$, however the submaxima remain approximately equal (Figure $9 \mathrm{~b}$ and $\mathrm{c}$ ).

For higher $\gamma$ values the submaxima on each side of ED become sharper but remain approximately equally populated unless the cells are allowed to pull-apart as soon as the gaps and the overlaps with their neighbours exceed a given threshold. The introduction of this new mode of accommodation between the cells results in the rapid increase of M1 at the expense of M2 (Figure 9d and 9e) similarly to that observed in ice. 


\section{DISCUSSION}

\section{Validity of the comparison with the geometrical model}

Disregarding for the moment the restriction of Etchecopar's model due to the rigid behaviour of the cells, it is believed that the striking analogy between the model and the ice aggregate basically originates in that ice deformed in plane strain fits particularly well with the two-dimensional nature of the model. In fact, let us consider the basal plane as the unique slip plane, six slip directions are equivalent in that plane due to the ice symmetry. For a given direction of the applied shear stress on the basal plane, it is expected that the resulting motion direction on that plane by simultaneous slip along the two nearest slip directions will be close to the direction of the applied stress. Introducing a power flow exponent into these geometrical considerations, Kamb (1961) showed that shear takes place exactly in the direction of the applied shear stress if the exponent of stress in the flow law equals 1 (Newtonian flow) or 3. In addition, the same considerations indicate that, for $n=3$, the angle between the crystallographic slip direction and the direction of the applied stress has no influence on the slip rate. More generally,

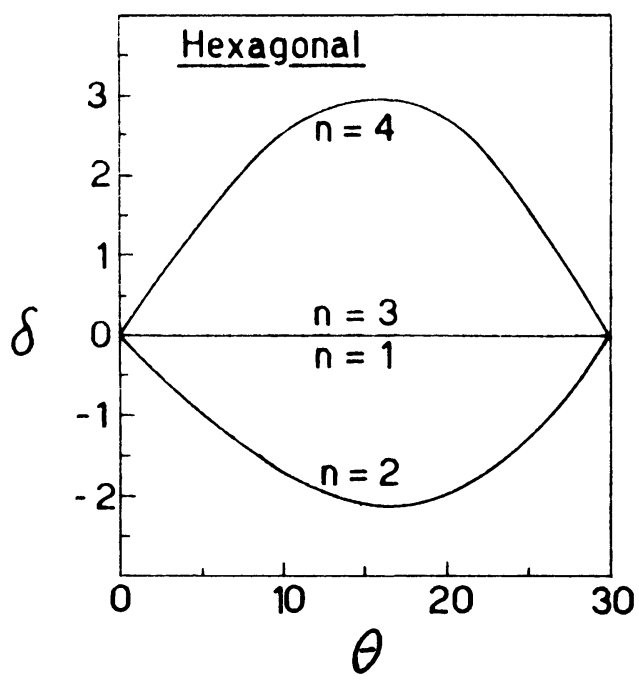

FIGURE 10 Response of a hexagonal crystal to simultaneous slip on (0001) (Kamb, 1961, Figure 4). The deviation $\delta=\theta-\phi$ between the direction $\theta$ of the resolved shear stress on (0001) and the direction $\phi$ of the resulting motion is plotted, in degrees, as a function of $\theta$ for four values of the power-law exponent $n . \delta>0$ represents deviation towards the nearest slip direction, $\delta<0$ deviation away from it. 
it is shown that the maximum deviation between the direction of the resolved shear stress on (0001) and the direction of the resulting motion never exceeds $3^{\circ}$ for $1 \leqslant n \leqslant 4$ (Figure 10). The currently accepted values for $n$ are around 3 (plasticity by dislocation creep) in the usual domain of shear stresses (Duval, 1976b). Thus, if one accepts Kamb's demonstration, it can be concluded that the trace of the slip plane in the plane of the deformation is parallel to the slip direction for ice. This is the basic assumption for Etchecopar's twodimensional aggregate.

\section{M1 and M2 submaxima}

In the geometrical model, the evolution of each cell can be followed step by step with increasing shear strain (Etchecopar, 1974). In short, it is observed that each submaximum derives from a given set of initial cells, corresponding to a given angular domain for the $\delta_{0}$ initial orientations of their slip direction:

1) In the $\delta_{0}=+50^{\circ}$ to $-30^{\circ}$ range (Figure 11), positive (i.e. conformable to the sense of the external shear) slip occurs in the corresponding cells and, with the help of minor positive or negative external rotations, the slip directions progressively rotate towards the shear direction (Figure 11a). This group of cells gives birth to the M1 submaximum.

2) In the $\delta_{0}=+90^{\circ}$ to $+50^{\circ}$ and $-30^{\circ}$ to $-90^{\circ}$ ranges, slip within the cells is variable in intensity and negative in sense. Large external rotations occur, always positive, tending to rotate the slip directions towards SD. Slip plus rotation is much larger for cells with $\delta_{0}$ close to the $-30^{\circ}$ angular boundary (Figure 11b). But, as the cells are progressively elongated parallel to their neighbours (about ED) they cannot rotate or deform any more by slip as the resolved shear stress on the slip lines has a low value for such orientations. The cells become locked like a row of books tilted over on a shelf.

In the model, the M2 submaximum sharpens and rotates passively towards ED as ED itself rotates towards SD as strain increases. Unlocking is achieved by a sub-division of the locked cells, giving smaller and more isodiametric cells which then undergo positive slip and rotation (Figure 11c).

These basic processes are also thought to be valid for ice except that the mechanisms helping the grain-boundary fitting and the unlocking of the grains are different. Additional rotation due to kink-bands and dislocation subboundaries within the grains is probably one of these processes, high angle prismatic subboundaries are frequently observed in thin section. The kinkbands may evolve through polygonization into new independent grains of similar lattice orientations. Syntectonic recrystallization and grain-boundary 
This implies that once such a textural zone is created inside a glacier, it will preferentially deform at the expense of the rest of the ice (see also Russel-Head and Budd, 1979).

\section{Foliation in ice}

This term usually describes the various layered or planar structures that appear in glaciers, made visible by colour contrasts due to the variable impurity contents or bubble densities (Hooke and Hudleston, 1978). Foliation is restricted here to its microstructural meaning viz. the average flattening plane of the grains or, in a section parallel to the plane of the deformation, the average elongation direction. In fact, ice deformed near the melting point (Alpine glaciers or experimentally) involves a high mobility of the grainboundaries and hardly shows any foliated microstructures (see Kamb, 1972; Duval, 1976a). In our experiments, the temperature is rather high $\left(\mathrm{T}=-7^{\circ} \mathrm{C}\right.$ to $-12^{\circ} \mathrm{C}$ ) but the grain-boundary mobility seems sufficiently suppressed to give rise to a faint foliation (Figure 4). Note that the basal plane probably acts as a privileged grain-boundary plane as indicated by the widening of the maximum towards SD in Figure 4b. It has also been observed (see Gow and Williamson, 1976; Figure 11) that dirty ice has a foliated structure due to the slower grain-boundary mobility (Wilson, 1979).

The above observations favorably compare with microstructural observations in rocks such as subsolidus and low-temperature peridotites (olivine rich aggregates) which always show a well-defined foliation (porphyroclastic microstructure). This is not the case for high-temperature deformed dunites (pure olivine aggregates, see Cassard, 1980). In high-temperature deformed quartzites a small amount of impurities (a few percent of micas is sufficient) is necessary to observe clearly a grain-shape elongation (Bouchez and Pêcher, 1981).

If a foliation can be determined in the ice aggregate (let us call it ED if it is close to the theoretical one for simple shear), it is interesting to note that the unequivocal angular relationship between ED and M1 can be used to predict the sense of shear. For a well-defined foliation, this angle should also be an estimate of the total shear strain but, in natural cases, the simple shear hypothesis is not always applicable during the whole strain history and therefore the obliquity criterion is only valid for the rotational component of strain and not necessarily for strain estimates.

\section{Acknowledgements}

This paper is dedicated to Professor Bruno Sander (1885-1979) a forerunner in fabric studies (Sander, 1970). The study was supported by the C.N.R.S. (ERA 547 and A.T.P. Tectonophysique 
1979). A. Cossard and M. C. Bréhier are thanked for the technical assistance. A. Nicolas, F. Boudier and G. Lister are thanked for their critical readings of the manuscript.

\section{References}

Bouchez, J. L., Dervin, P., Mardon, J. P. et Englander, M. La diffraction neutronique appliquée à l'étude de l'orientation préférentielle de réseau dans les quartzites, Bull. Minéral. 102, 225-231 (1979).

Bouchez, J. L. and Pêcher, A. The Himalayan Main Central Thrust pile and its quartz-rich tectonites in Central Nepal, Tectonophysics 78, 23-50 (1981).

Cassard, D. Structure et origine des gisements de chromite du Massif du Sud-Ophiolites de Nouvelle-Calédonie. Thesis Univ. of Nantes (1980).

Christie, J. M., Griggs, D. T. and Carter, N. L. Experimental evidence of basal slip in quartz, J. Geol. 72, 734-756 (1964).

Duval, P. Fluage et recristallisation des glaces polycristallines. Thesis Univ. of Grenoble (1976a).

Duval, $P$. Lois de fluage transitoire ou permanent de la glace polycristalline pour divers états de contrainte, Ann. Géophysique 32(4), 335-350 (1976b).

Duval, P. Creep and fabrics of polycrystalline ice under shear and compression, J. Glaciol. 27, 129-140 (1981).

Etchecopar, A. Simulation par ordinateur de la déformation progressive d'un agrégat polycristallin. Thesis Univ. of Nantes (1974).

Etchecopar, A. A plane kinematic model of progressive deformation in a polycrystalline aggregate, Tectonophysics 39, 121-139 (1977).

Glen, J. W. The mechanics of ice. Cold regions Research and Engineering Laboratory, Hanover, New Hampshire, Monograph II C2 (1975).

Glen, J. W. and Jones, S. J. The deformation of ice single crystals at low temperatures. In: Oûra, H. (ed.) Physics of snow and ice. Sapporo, 1: 267-275 (1967).

Gow, A. J. and Williamson, T. Rheological implications of the internal structure and crystal fabrics of the West Antarctic ice sheet as revealed by deep core drilling at Byrd Station. C.R.E.L. Report 76-35, 1-25 (1976).

Hobbs, P. Ice physics. Clarendon Press, Oxford (1974).

Hooke, R. L. and Hudleston, P. J. Origin of foliation in glaciers, J. Glaciol. 20, 285-299 (1978).

Higashi, A. Mechanisms of plastic deformation in ice single crystals. In: Oûra, H. (ed.) Physics of Snow and Ice. Sapporo, 1: 277-289 (1967).

Hudleston, P. J. Progressive deformation and development of fabric across zones of shear in glacial ice. In: Saxena, S. K. and Bhattacharji, S. (eds.) Energetics of Geological Processes. Springer-Verlag, New York, 121-150 (1977).

Kamb, W. B. Ice petrofabric observations from Blue Glacier, Washington, in relation to theory and experiments, J. Geophys. Res. 64(11), 1891-1909 (1959).

Kamb, W. B. The glide direction in ice, J. Glaciol. 3, 1097-1106 (1961).

Kamb, W. B. Experimental recrystallization of ice under stress. Am. Geophys. Union Monog. 16, 211-241 (1972).

Le Gac, H. Contribution à la détermination des lois de comportement de la glace polycristalline (anélasticité et plasticité). Thesis, Univ. Grenoble (1980).

Le Gac, H., Meyssonier, J. and Duval, P. Relation entre le comportement plastique de la glace polycristalline et la texture cristalline. Coll. Intern. C.N.R.S. "Comportement mécanique des solides anisotropes". Villars de Lans. June 1980 (1981).

MacCornell, J. C. On the plasticity of an ice crystal. Proc. Roy. Soc. of London 299, 323-343 (1891).

Mugurama, J. and Higashi, A. Non-basal glide bands in ice crystal. Nature 198, 573 (1963).

Nicolas, A., Bouchez, J. L., Boudier, F. and Mercier, J. C. Texture, structures and fabrics due to solid state flow in some European lherzolites. Tectonophysics 12, 55-86 (1971).

Nicolas, A. and Poirier, J. P. Crystalline plasticity and solid state flow in metamorphic rocks. Wiley Inter Science, London (1976). 
Nicolas, A. et Vialon, P. Les mécanismes de déformation ductile dans les roches. Soc. Géol. France, Mémoire 10, 127-139 (1980).

Rigsby, G. P. Crystal fabric studies on Emmon Glacier, Mount Rainier, Washington, J. Geol. 59, 590-598 (1951).

Russel-Head, D. S. and Budd, W. F. Ice-sheet flow properties derived from bore-hole shear measurements combined with ice-core studies. J. Glaciol. 24, 117-130 (1979).

Sander, B. An introduction to the study of fabrics of geological bodies. Pergamon (1970).

Schumsky, P. A. Principes de glaciologie structurale. Annales du Centre d'Etudes et de Documentation Paléontologiques, C.N.R.S. (1965).

Steinemann, S. Experimentalle Untersuchungen zur Plastizität von Eis. Beitrage zür Geologie der Schweiz, Hydrologie. 10, 1-72 (1958).

Wilson, C. J. L. Boundary structures and grain shape in deformed multilayered polycrystalline ice. Tectonophysics 57, T19-T25 (1979).

Wilson, C. J. L. Texture and grain growth during the annealing. Textures and Microstructures 5, 19-32 (1982). 